\title{
Silica-coated Magnetic Nanocomposites as an Adsorbent for the Removal of Methylene Blue Dyes from Water: Preparation and Characterization
}

\author{
Jing $\mathrm{Yu}^{\mathrm{a}}$, Debin Jiang ${ }^{\mathrm{b}}$, Qi $\mathrm{Hao}^{\mathrm{c}}$ and Jianying Liu ${ }^{\mathrm{d}}$ \\ College of Resources and Environment, Chengdu University of Information Technology, Chengdu \\ 610225, China

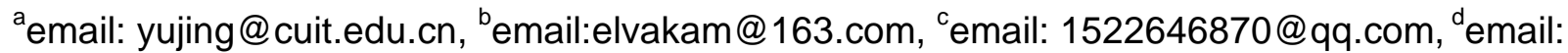 \\ 740036253@qq.com
}

Keywords: Silica-Coated; Mn-Zn ferrite; Magnetic; Nanocomposite; Adsorbent; Methylene blue.

Abstract: A novel magnetic nanocomposites (MNCs) adsorbent was synthesized for the removal of methylene blue (MB) dyes from wastewater. The inner core $\mathrm{Mn}_{0.6} \mathrm{Zn}_{0.4} \mathrm{Fe}_{2} \mathrm{O}_{4}$ magnetic nanoparticles (MNPs) were coated with an outer shell of silica based on a facile method using tetraethylorthosilicate (TEOS) as a precursor material. The optimum conditions of preparation were gotten. The observed BET surface area and pore volume of MNCs all increased, which makes it useful for adsorption of MB dyes. It was confirmed that the MNCs adsorbent was synthesized with large surface area, suitable pore size, and uniform pore size distribution, but the material possessed irregular pore structures by HRTEM. The synthesized silica-coated Mn-Zn ferrite MNCs were nanosized microspheres with a special "core/shell" structure. The Mn-Zn ferrite MNCs exhibited a good dispersibility and magnetic separability in water. The nanosize and fast separation from water make silica coated Mn-Zn ferrite MCPs adsorbent a potential claimant for environmental applications.

\section{Introduction}

At present, the treatment of azo dye wastewater is still a big difficult problem in China. Methylene blue (MB) dyes is an organic azoic compound and extensively used in the textile, leather, paper and other industries. It usually present in the effluents of these industries. The presence of $\mathrm{MB}$ dyes in wastewaters, even in low concentrations, is a major concern because it is highly visible, toxic to microorganisms and harmful to human health. Without reasonably processing, it can cause serious environment pollution since it is toxic to microorganisms and can impede the photosynthesis of aqueous flora [1]. Even worse, most of the organic dyes are harmful to human being due to their potential mutagenic and carcinogenic effects. Therefore, the removal of MB dyes from wastewater has been seriously concerned.

In recent decades, many methods have been investigated for the removal of dyes from wastewaters, such as chemical oxidation, biodegradation, membrane separation, electrochemical processes, coagulation/flocculation and adsorption [2,3].Adsorption is a conventional technique to remove dyes from wastewaters, since it is simple, highly efficiently and easy of operation. The activated carbon as an adsorbent has a long history and it has been widely used for the dye removal from the wastewater. However, due to its difficult solid-liquid separation performance, researchers have been studying alternative adsorbents .

The magnetic nanocomposites (MNCs) have gained increasingly attention in magnetic resonance imaging, targeted drug delivery, hyperthermia and magnetic separation owing to their strong magnetism, favorable water-dispersion, biocompatibility and tunable shell.The MNCs using as magnetic adsorbents could be separated easily and quickly from the aqueous solution under an external magnetic field[4]. The adsorption of MNCs has attracted great attention as an innovative ways of dyes treatment.

The MNCs used as adsorbents always have the "core/shell" structure. In recent years, there has been an escalating interest in functionalizing/coating the surface of magnetic nanoparticles (MNPs) with inorganic/organic materials. 
Among inorganic materials, silica is the most preferred stabilizer. Silica is known to be biocompatible and chemically inert, so it does not affect the redox reaction at the core surface .It screens the magnetic dipolar interaction between MNPs, thus preventing their aggregation; this favours their dispersion in liquid media, protects them from leaching in an acidic environment, the existence of abundant silanol groups on the silica layer allows various functional groups for bio-conjugation to be activated on the coated surface. Unlike polymers, it is not subject to microbial attack and it neither swells nor changes porosity in response to the environmental $\mathrm{pH}$ values . In this sense, silica is a very important technological material with potential to improve the properties of MNPs and tailor their use. A variety of methods have been reported in the literature to form silica coatings onto the surface of MNPs, including sol-gel processing, CVD technique, hydrolysis of tetraethoxysilane (TEOS), and so on. The core is usually in the form of $\mathrm{Fe}_{3} \mathrm{O}_{4}$ or its oxidized product $\gamma-\mathrm{Fe}_{2} \mathrm{O}_{3}$. Since the $\mathrm{Fe}_{3} \mathrm{O}_{4}$ magnetic nanoparticles (MNPs) contains $\mathrm{Fe}^{2+}$, which is easy to be oxidized to be $\mathrm{Fe}^{3+}$, the $\mathrm{Fe}_{3} \mathrm{O}_{4} \mathrm{MNPs}$ are vulnerable to lose magnetism. To improve the oxidation resistance of $\mathrm{Fe}_{3} \mathrm{O}_{4}, \mathrm{Fe}^{2+}$ is partly replaced by manganese and zinc, and manganese zinc $(\mathrm{Mn}-\mathrm{Zn})$ ferrite $\left(\mathrm{Mn}_{1-\mathrm{x}} \mathrm{Zn}_{\mathrm{x}} \mathrm{Fe}_{2} \mathrm{O}_{4}\right)$ is prepared. $\mathrm{Mn}-\mathrm{Zn}$ ferrite MNPs should be a well substitute for $\mathrm{Fe}_{3} \mathrm{O}_{4}$ MNPs.

The magnetic separation properties of silica-coated $\mathrm{Mn}-\mathrm{Zn}$ ferrite MNCs are determined by bare $\mathrm{Mn}-\mathrm{Zn}$ ferrite MNPs. Mn-Zn ferrite $\left(\mathrm{Mn}_{1-\mathrm{x}} \mathrm{Zn}_{\mathrm{x}} \mathrm{Fe}_{2} \mathrm{O}_{4}\right) \mathrm{MNPs}$ is a kind of solid solution whose magnetic moment changes with its $\mathrm{Zn}$ content. For $\mathrm{Zn}$ content lower than $40 \%$, magnetization increases with $\mathrm{Zn}$ content; when the $\mathrm{Zn}$ content further increases beyond $40 \%$, magnetization declines. Therefore, for $\mathrm{Zn}$ content of $40 \%, \mathrm{Mn}_{0.6} \mathrm{Zn}_{0.4} \mathrm{Fe}_{2} \mathrm{O}_{4}$ reaches the highest magnetization [5].

However, in published literature, only the synthesis of silica-coated Mn- $\mathrm{Zn}$ ferrite $\left(\mathrm{Mn}_{0.4} \mathrm{Zn}_{0.6} \mathrm{Fe}_{2} \mathrm{O}_{4}\right)$ MNCs has been attempted [6], while limited information is available on the application of the silica-coated Mn-Zn ferrite MNCs as adsorbents for the removal of MB dyes from wastewater.

The objective of this work is to investigate the preparation of silica-coated $\mathrm{Mn}-\mathrm{Zn}$ ferrite $\left(\mathrm{Mn}_{0.6} \mathrm{Zn}_{0.4} \mathrm{Fe}_{2} \mathrm{O}_{4}\right)$ MCPs adsorbents using TEOS as a precursor material for silica. The silica-coated $\mathrm{Mn}-\mathrm{Zn}$ ferrite MCPs adsorbents were then used for removal of the cationic dyes of MB from aqueous solution. The optimal preparation conditions of silica-coated ferrite MCPs were determined by the removal efficiency of MB dyes. Our present finding may shed a light on using of a new wastewater purification method in the environment protection industry.

\section{Experimental}

\section{Materials}

All the chemicals used for the experiment were of analytical grade. Ferric nitrate nonahydrate $\left(\mathrm{Fe}\left(\mathrm{NO}_{3}\right)_{3} \cdot 9 \mathrm{H}_{2} \mathrm{O}\right)$, Zinc nitrate hexahydrate $\left(\mathrm{Zn}\left(\mathrm{NO}_{3}\right)_{2} \cdot 6 \mathrm{H}_{2} \mathrm{O}\right)$, manganous nitrate aqueous $\left(\mathrm{Mn}\left(\mathrm{NO}_{3}\right)_{2}, 50 \mathrm{wt} \%\right)$, sucrose, citric acid monohydrate $\left(\mathrm{C}_{6} \mathrm{H}_{8} \mathrm{O}_{7} \cdot \mathrm{H}_{2} \mathrm{O}\right)$, ammonia aqueous $\left(\mathrm{NH}_{3} \cdot \mathrm{H}_{2} \mathrm{O}\right)$, methylene blue(MB) and tetraethylorthosilicate (TEOS), were purchased from a local company in Chengdu. All the chemicals were used without any further purification.Distilled water was used throughout the experiments.

\section{Preparation of silica-coated Mn-Zn ferrite magnetic nanocomposites}

$0.5 \mathrm{~g}$ of Mn-Zn ferrite MNPs[7] and $150 \mathrm{ml}$ of citrate acid solution with a concentration of $0.05 \mathrm{~mol} / \mathrm{L}$ were mixed together in a flask. To reduce the aggregation of Mn-Zn MNPs, the mixture was vigorously stirred as follows: at first, the mixture was vigorously stirred at $400 \mathrm{r} / \mathrm{min}$ for $3 \mathrm{hr}$ at $40^{\circ} \mathrm{C}$ , and then the $\mathrm{pH}$ of the mixture was adjusted to be 5.5 or so using $\mathrm{NH}_{3} \cdot \mathrm{H}_{2} \mathrm{O}$, and sequentially stirred for additional $3 \mathrm{hr}$ at $40^{\circ} \mathrm{C}$.Afterwards, the required amounts of ammonia solution and TEOS solution were slowly added respectively. The mixed solution was mechanically stirred for $6 \mathrm{hr}$, resulting in formation of silica-coated Mn-Zn ferrite MNCs.After 6hr stirring, Mn-Zn ferrite MNCs were magnetically 
separated by placing the mixed solution on a magnetic slab of surface field $0.2 \mathrm{~T}$. The Mn- $\mathrm{Zn}$ ferrite MNCs settled at the bottom and the solution was carefully removed by a syringe. The obtained product was washed several times with dry ethanol by suction filtration until the $\mathrm{pH}$ of the filter liquor decreased to 7.0. It was dried in a vacuum oven at $60^{\circ} \mathrm{C}$ for $5 \mathrm{hr}$. Finally, silica-coated Mn-Zn ferrite MNCs were obtained. In all experiments, the flask was placed in a thermostat heating mantle to maintain the required temperature.

\section{Characterization}

The BET specific surface area (SSA) of silica-coated ferrite MNCs samples were defined by $\mathrm{N}_{2}$ adsorption-desorption isotherms $(77 \mathrm{~K})$ using a SSA-4220 micromeritics instrument (Builder, China). The bare and silica-coated $\mathrm{Mn}_{0.6} \mathrm{Zn}_{0.4} \mathrm{Fe}_{2} \mathrm{O}_{4}$ MNPs were also characterized by High-resolution Transmission Electron Microscopy (HRTEM)(JEM-2100F, Jeol, Japan) after the sample was mixed with pure ethanol in an ultrasonic apparatus and superimposed on a lacey carbon film supported on $\mathrm{Cu}$ grid to prevent eventual agglomeration. The HRTEM image were obtained.The hysteresis (B-H) loop of the bare and silica-coated $\mathrm{Mn}_{0.6} \mathrm{Zn}_{0.4} \mathrm{Fe}_{2} \mathrm{O}_{4}$ MNPs was measured via vibrating specimen magnetometer (VSM)(BHV-525, Riken Denshi,Japan) at room temperature, where the maximum applied magnetic field for the measurements is $1.5 \mathrm{~T}$.

\section{MB dyes removal experiment}

MB dyes removal experiments with Mn-Zn ferrite MNCs adsorbents were performed in $250 \mathrm{~mL}$ beaker containing $100 \mathrm{~mL}$ of $\mathrm{MB}$ dyes solution with known initial concentration $50 \mathrm{mg} / \mathrm{L}$ and $80 \mathrm{mg}$ of silica-coated Mn-Zn ferrite MCPs. The mixture was shaken in an oscillator (THZ-82, Taicang City, China) at $200 \mathrm{r} / \mathrm{min}$ and $25^{\circ} \mathrm{C}$ for a predefined time, and the beaker was then placed on the magnet for $4 \mathrm{~min}$. The MB dyes loaded Mn-Zn ferrite MNCs were separated magnetically. The dye solution became colorless after stripping. The dye solution above the $\mathrm{Mn}-\mathrm{Zn}$ ferrite MNCs was removed completely. The initial and final MB dye concentrations were determined with a spectrophotometer (UV-2250, Shimadzu, Japan) at wavelength of $664 \mathrm{~nm}$. The percentage removal efficiency (R \%) of MB were calculated: $\% R=100 \times\left(C_{0}-C_{f}\right) / C_{0}$, where $C_{0}(m g / L)$ and $C_{f}(m g / L)$ are the initial and final $M B$ concentrations, respectively.

\section{Results and discussion}

\section{Preparation of Mn-Zn ferrite MCPs}

Fig.1(a) shows the removal efficiency of MB using bare Mn-Zn ferrite MNPs, silica and silica-coated $\mathrm{Mn}-\mathrm{Zn}$ ferrite MCPs respectively. Obviously, the removal efficiency of MB using silica-coated Mn-Zn ferrite MCPs was higher than the sum of the other two samples, indicating that the MCPs has synergistic effect for MB removal. It was because the silica-coated ferrite MCPs could be well dispersed in aqueous phase with larger specific surface area than bare ferrite MNPs, and there were also abundant silanol groups on the silica layer. All of those were advantageous to the MB removal. 

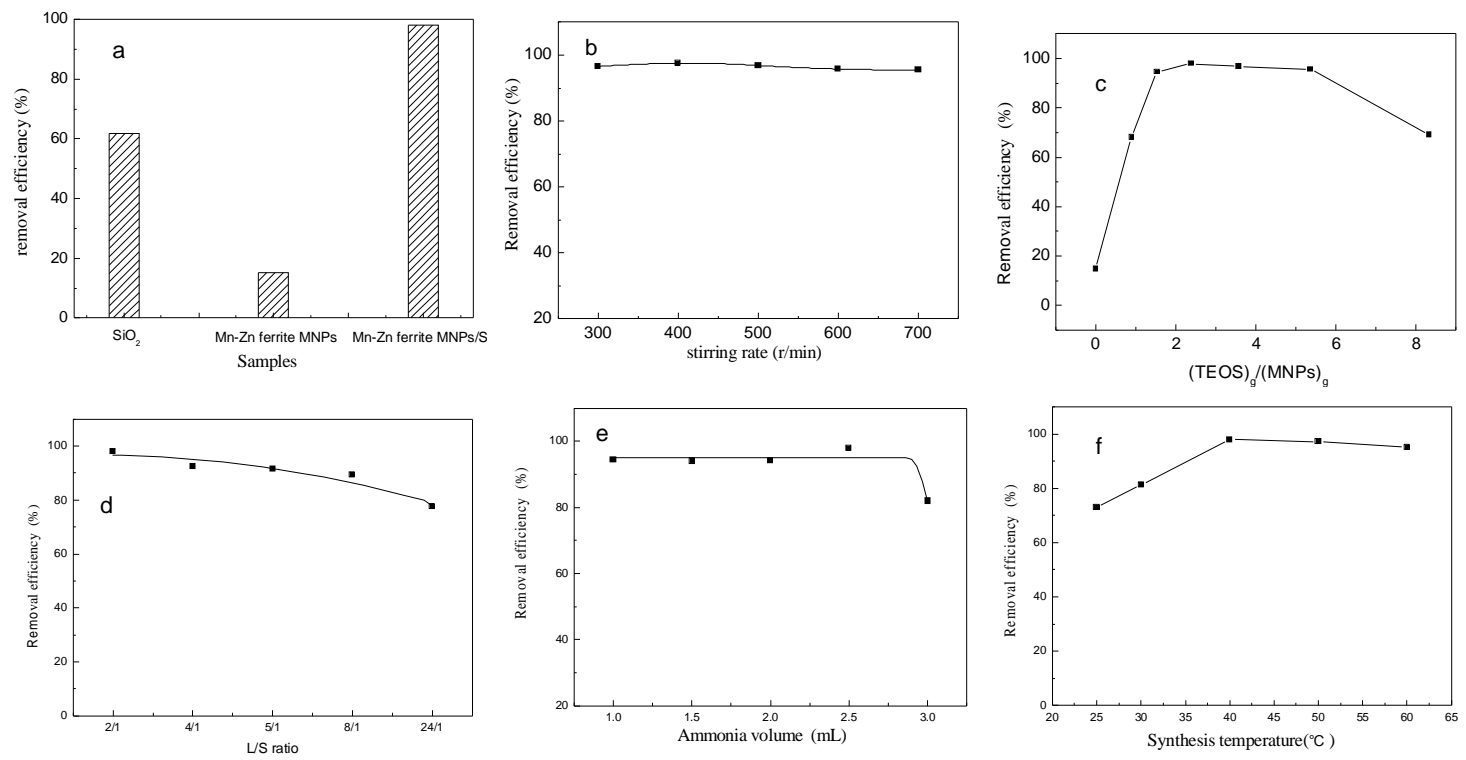

Fig.1 Effect of various parameters on the preparation of Silica-coated Mn-Zn ferrite MCPs

The effect of stirring rate on synthesis of silica-coated Mn-Zn ferrite MNCs is shown in Fig.1(b). It was found that the removal efficiency of MB reached $97 \%$ when the stirring rate of preparation was 400 $\mathrm{r} / \mathrm{min}$. It could be attributed to the fact that the lower stirring rate could not well reduce the MNPs aggregation. The lower stirring rate of preparation has negative effect on synthesizing silica-coated MNCs. The optimum stirring rate of preparation is $400 \mathrm{r} / \mathrm{min}$.

In order to investigate the effect of TEOS dosage, the preparation was evaluated using different ratios between TEOS mass (g) and Mn-Zn ferrite MNPs mass (g) for constant volume of TEOS. The experimental results are indicated in Fig.1(c).It was found that the (TEOS $)_{\mathrm{g}} /(\mathrm{MNPs})_{\mathrm{g}}$ increased and the MNPs could be well dispersed, reducing the aggregation of MNPs. The removal efficiency of MB was the biggest when the (TEOS) $)_{\mathrm{g}} /(\mathrm{MNPs})_{\mathrm{g}}$ was 2.4-3.6 because of larger specific surface area and abundant silanol groups on the silica layer of MNPs. On the other hand, when the (TEOS $)_{\mathrm{g}} /(\mathrm{MNPs})_{\mathrm{g}}$ is higher enough, beyond 3.6, the size of MNCs might increase and the surface area of MNCs decreased. The optimum (TEOS) $)_{\mathrm{g}} /(\mathrm{MNPs})_{\mathrm{g}}$ is 2.4-3.6.

The $\mathrm{L} / \mathrm{S}$ ratio is the ratio between volume $(\mathrm{mL})$ of TEOS solution, while Mn- $\mathrm{Zn}$ ferrite MNPs mass $(\mathrm{g})$ when (TEOS $)_{\mathrm{g}} /(\mathrm{MNPs})_{\mathrm{g}}$ is constant. The solvent of TEOS solution is absolute ethanol.

The effect of L/S ratio on synthesis of silica-coated Mn-Zn ferrite MNCs is shown in Fig.1(d). The removal efficiency of $\mathrm{MB}$ decreased gradually with increasing of $\mathrm{L} / \mathrm{S}$ ratio obviously. Higher L/S ratio has negative effect on synthesizing of MNCs. It was because the solvent of absolute ethanol was contributed to aggregation of Mn-Zn ferrite MNPs leading to smaller specific surface area of MNCs, and, as a consequence, the removal efficiency of $\mathrm{MB}$ decreased. The optimum L/S ratio is 2.5:1 with less absolute ethanol.

The effect of ammonia volume on synthesis of silica-coated Mn-Zn ferrite MCPs is shown in Fig.1(e).The removal efficiency of MB decreased gradually with increasing the ammonia volume. The hydrolysis of the alkoxy groups of the silica precursor (TEOS) leads to the formation of silanol groups ( $\mathrm{Si}-\mathrm{OH})$.Ammonia solution neutralizes the $\mathrm{pH}$ of the mixture, shifting the reaction to basic conditions where the hydroxide anions play the role of basic catalysts for the poly-condensation. This step leads to the formation of oxo-bridged $\mathrm{Si}-\mathrm{O}-\mathrm{Si}$ groups and therefore to the interconnectivity of the silica network [8].Higher ammonia volume is advantageous to the hydrolysis reaction of TEOS. The hydrolysis reaction rate is faster and larger size silica-coated MCPS are obtained. The optimum ammonia volume is $2.5 \mathrm{~mL}$.

The effect of hydrolysis reaction temperature on synthesis of silica-coated $\mathrm{Mn}-\mathrm{Zn}$ ferrite MNCs is shown in Fig.1(f).Hydrolysis reaction is endothermic, and condensation reaction is endothermic; the hydrolyzate, silanol, dissolves in water immediately and releases a large amount of heat, exceeding the 
absorption heat of hydrolysis recation. On the other hand, the high temperature leads to ammonia volatilization against the hydrolysis reaction.It was found that the removal efficiency of $\mathrm{MB}$ nearly reached $98 \%$ when the hydrolysis reaction temperature was $40^{\circ} \mathrm{C}-50^{\circ} \mathrm{C}$. The optimum hydrolysis reaction temperature is $40^{\circ} \mathrm{C}-50^{\circ} \mathrm{C}$.

\section{Characterization of silica-coated Mn-Zn ferrite MNCs}

Silica coating has been confirmed by FT-IR and XRD of silica-coated Mn-Zn ferrite MCPs [9] .The porous nature of the prepared bare and silica-coated Mn-Zn ferrite MNPs was confirmed from nitrogen adsorption-desorption isotherms plot. The nitrogen adsorption-desorption isotherm and BJH pore-size distributions (PSDs) of bare MNPs and silica-coated MNCs are presented in Fig.2(a) and (b), respectively.

It can be seen that each sample exhibits an isotherm of type IV with a sharp inflection at a relative pressure around $\mathrm{P} / \mathrm{P}_{0}=0.40-0.50$, characterizing a capillary condensation inside the mesopores. Such adsorption behavior is typical for the mesoporous materials.

The hysteresis loop in the isotherm of bare MNPs refers to Type H3, which is observed with aggregates of plate-like particles giving rise to slit-shaped pores. While the hysteresis loop in the isotherm of silica-coated corresponds to Type H4, which is associated with narrow slit-like pore causing by layered structure [10].

As a result, we noticed the disappearance of the peaks around $3.0 \mathrm{~nm}$ and $5.5 \mathrm{~nm}$ on the pore size distribution plot of silica-coated MNCs. This might be caused by the reduced agglomeration of Mn- Zn ferrite MNPs and the silica coating on the surface of MNPs. BJH pore distributions (Fig.2c) for $\mathrm{N}_{2}$-MNPs show unequal pore size distribution in the range1-10nm, while BJH pore distributions (Fig.3d) for $\mathrm{N}_{2}$-MNCs show uniform pore size distribution with the maximum around $2.5 \mathrm{~nm}$. It was confirmed that the MNCs adsorbent was synthesized with large surface area, suitable pore size, and uniform pore size distribution.
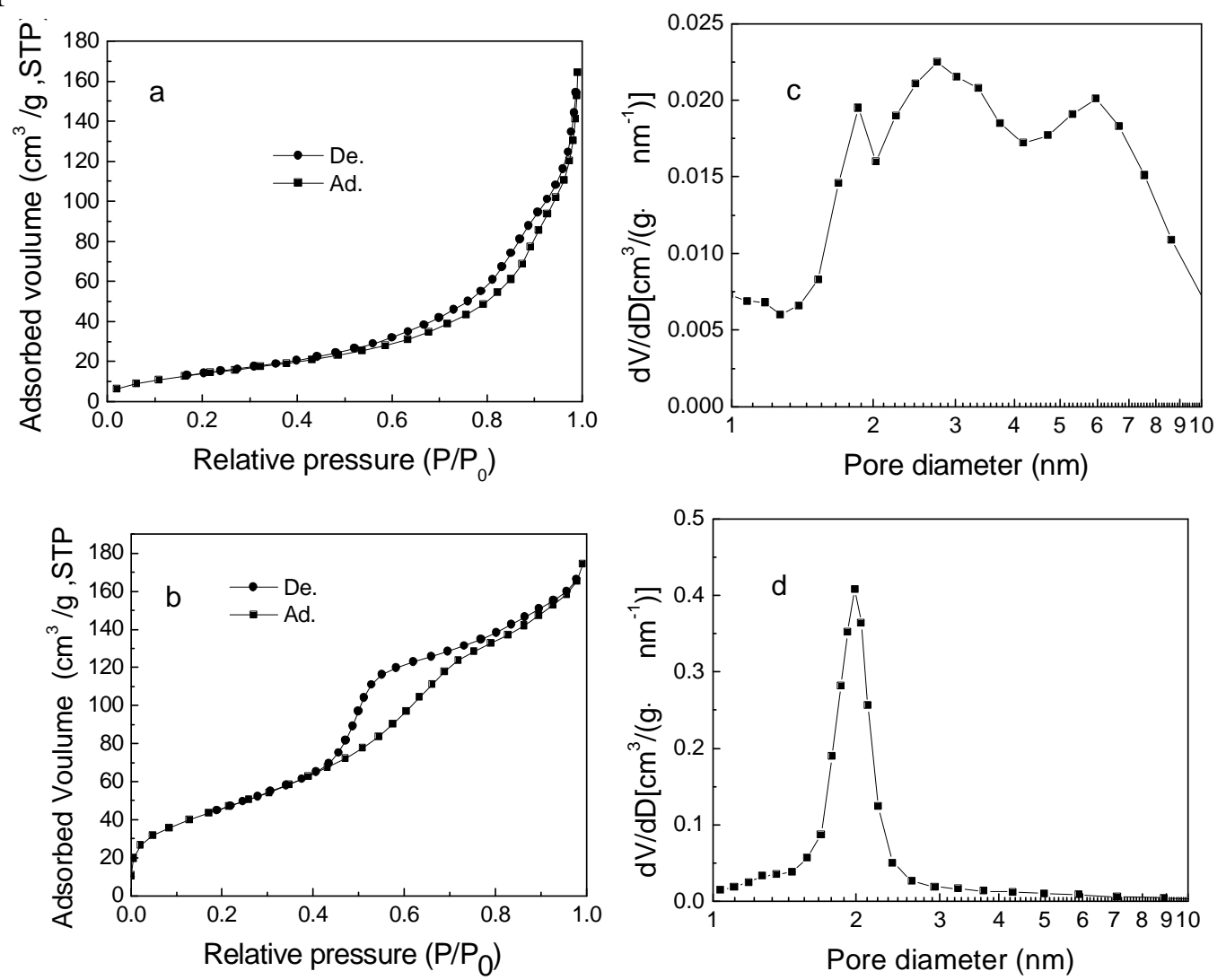

Fig.2 Nitrogen adsorption isotherms and PSDS of bare MNPs and silica-coated MNCs 
TEM and HRTEM studies were performed in order to understand the details of the morphology of bare and silica-coated Mn-Zn ferrite MNPs.

In Fig. 3(a), the single-crystallite lattice fringe patterns taken on a single nanoparticle can be well observed. Also, Fig. 3(a) clearly displays the lattice fringe along with the clear view of the coating layer of Silica. The lattice spacings between two adjacent planes is $0.1397 \mathrm{~nm}$ and $0.2386 \mathrm{~nm}$, which correspond very well to the d-spacing for the $\left(\begin{array}{lll}4 & 4 & 0\end{array}\right)$ and $\left(\begin{array}{lll}3 & 1 & 1\end{array}\right)$ lattice plane of $\mathrm{Mn}-\mathrm{Zn}$ ferrite nanoparticles, respectively.In the coating layer no signature of crystallization or fringe pattern has yet been observed which indicates that the coating layer of silica is in the amorphous state. Thus, it is clear that the MNCs are in the amorphous silica matrix in the core/shell structure.

The porous nanostructure was also observed from HRTEM analysis as shown in Fig. 3(a) and (b). As shown in Fig. 3(b), bare MNPs owned pores in agreement with the results of the nitrogen adsorption-desorption isotherm of bare MNPs. Their typical core-shell structure with the magnetic core and silica layer, can be perceived. In combination with the observations in the $\mathrm{N}_{2}$ adsorption/desorption isotherms, we could confirm that the silica shell had successfully coated on the surface of the Mn-Zn ferrite MNPS cores, as illustrated by Fig. 3(a), but the material possessed irregular pore structures.
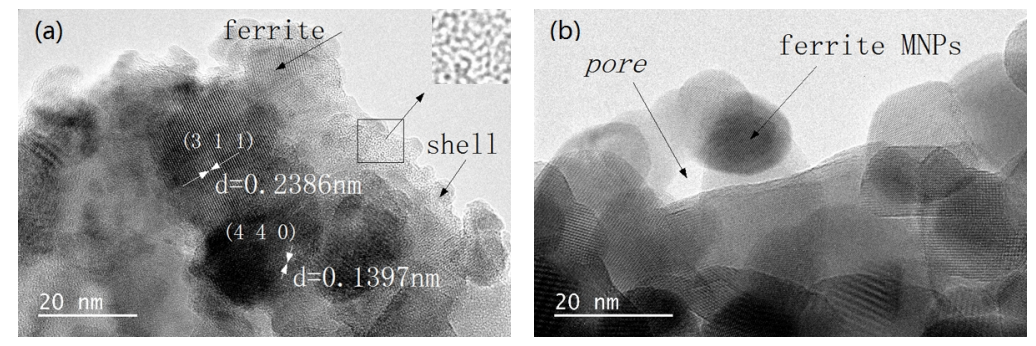

Fig.3HRTEM photographs and SAED patterns of bare and silica-coated MNPs

The hysteresis loops of the samples of bare and silica-coated Mn-Zn ferrite MNPs were studied by VSM, as shown in Fig.4.The saturation magnetization $\left(\mathrm{M}_{\mathrm{s}}\right)$ decrease from $26 \mathrm{emu} / \mathrm{g}$ to $18.6 \mathrm{emu} / \mathrm{g}$, due to the surface of MNPs is coated with a layer of amorphous silica.

The saturation magnetization $\left(M_{s}\right)$ of MNCs decreased, but the value of $M_{s}$ is sufficient enough to easily separate MNCs from water in an external magnet.The magnetic separation was tested by placing a Rb-Boron magnet $(0.2 \mathrm{~T})$ close to a conical flask which contained well-dispersed silica-coated MNCs in water.

It was observed that these silica-coated MNCs could be quickly separated from water (i.e., within 3 min) upon magnetic attraction. After removing the magnet, these particles could be easily redispersed in water upon slight shaking. Though the saturation magnetization of silica-coated MNCs decreased after silica coating (from $26 \mathrm{emu} / \mathrm{g}$ to $18.6 \mathrm{emu} / \mathrm{g}$ ), the remaining magnetism was still sufficient to achieve a fast separation from water under an external magnetic field.

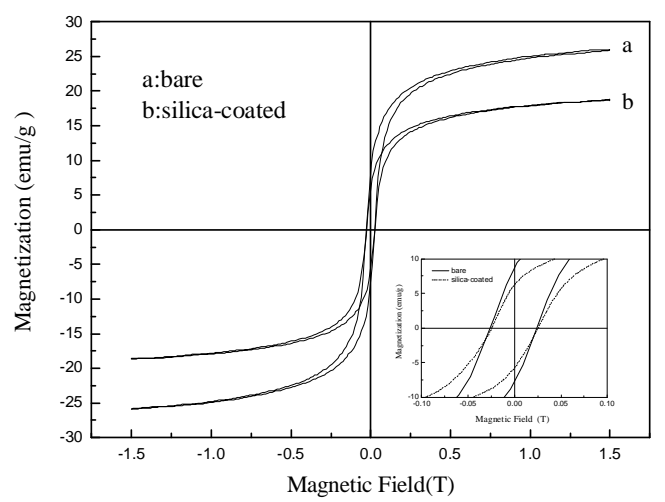

Fig.4 Magnetic hysteresis curves of bare and silica-coated $\mathrm{Mn}_{0.6} \mathrm{Zn}_{0.4} \mathrm{Fe}_{2} \mathrm{O}_{4}$ at room temperature 


\section{Conclusion}

Based on the experimental results, the following conclusions are drawn:

(1)When total disperse time was constant, the staged disperse way is optimum. The optimum conditions were gotten that (TEOS $)_{\mathrm{g}} /(\mathrm{MNPs})_{\mathrm{g}}$ is $2.4-3.6, \mathrm{~L} / \mathrm{S}$ ratio is $2.5: 1$, ammonia volume is $2.5 \mathrm{~mL}$ and hydrolysis reaction temperature is $40^{\circ} \mathrm{C}-50^{\circ} \mathrm{C}$.

(2) The observed BET surface area and pore volume of MNCs all increased, which makes it useful for adsorption of MB dyes. HRTEM observations confirm the presence of silica and pores on the bare and silica-coated Mn-Zn ferrite MNPs, but the material possessed irregular pore structures.

(3) Both bare as well as silica-coated Mn-Zn ferrite MNPs exhibit ferromagnetic behaviour with magnetic saturation of $26.0 \mathrm{emu} / \mathrm{g}$ and $18.6 \mathrm{emu} / \mathrm{g}$, respectively. This reduction is attributed to the formation of magnetically dead layer of silica.

Subsequent efforts should be focused on the adsorption kinetics, isotherm, the mechanism analysis as well as desorption experiments.

\section{Acknowledgments}

This study was supported by the Scientific Reserch Fund of SiChuan Provincial Education Department (15ZA0189).

\section{References}

[1]E.C. Lima, B. Royer, J.C.P. Vaghetti, N.M. Simon, B.M. da Cunha, F.A. Pavan, E. V. Benvenutti, R.C. Veses, C. Airoldi, Application of Brazilian-pine fruit coat as abiosorbent to removal of Reactive Red 194 textile dye from aqueous solution. kinetics and equilibrium study. J. Hazard. Mater. 155 (2008) 536-550.

[2]B. Mondal, V. C. Srivastava, J. P. Kushawaha, R. Bhatnagar, S. Singh, I. D. Mall, Parametric and multiple response optimization for the electrochemical treatment of textile printing dye-bath effluent. Sep. Purif.Technol. 109 (2013) 135-143a

[3]I. Vergili, Y. Kayaa, U. Sen, Z. B.Gönder, C. Aydiner, Techno-economic analysis of textile dye bath wastewater treatment by integrated membrane processes under the zero liquid discharge approach . Resour. Conserv. Recy. 58(2012)25-35.

[4]N. Yamamura, M. Higashi, N. Behera, J.Y. Wakaon, Evolution of mutualism through spatial effects. J. Theor. Biol. 226 (2004)421-428.

[5] Lu Xiao, Tao Zhou, Jia Meng, Hydrothermal synthesis of Mn-Zn ferrites from spent alkaline Zn-Mn batteries Particuology. 7(2009)491-495.

[6]S. Modak, S.Karan, S.K.Roy, S.Mukherjee, D.Das, P.K.Chakrabarti, Preparation and characterizations of $\mathrm{SiO}_{2}$-coated nanoparticles of $\mathrm{Mn}_{0.4} \mathrm{Zn}_{0.6} \mathrm{Fe}_{2} \mathrm{O}_{4}$. J. Magn. Magn. Mater. 321 (2009)169-174.

[7]Hailang. Qiu, Preparation of Mn-Zn Ferrite by Sucrose-Nitrate Method from Spent Alkaline Manganese Batteries as Resource Materials and Application of Mn-Zn Ferrite, thesis, Chengdu University of Information Technology, 2015.( In Chinese)

[8]H. Ramadan, T. Coradin, S. Masse, H. EI-Rassy, Synthesis and Characterization of Mesoporous Hybrid Silica-Polyacrylamide Aerogels and Xerogels. Silicon 3 (2011) 63-75.

[9] Debin Jiang, Jing Yu, Qingfeng Cheng, Xueqiao Zhang. Preparation and Characterization of Composite Magnetic Material Mn-Zn Ferrite/ $/ \mathrm{SiO}_{2}$. Environmental Protection of Chemical Industry, 35 (2015)536-541.( In Chinese)

[10]K.S.W. Sing, D.H. Everett, R.A.W. Haul, L. Moscou, R.A. Pierotti, J. Rouquerol, T. Siemieniewska, Reporting physisorption data for gas/solid systems with special reference to the determination of surface area and porosity. Pure. Appl. Chem. 57(1985)603-619. 